\title{
População, Urbanização e Globalização da Agricultura: \\ Notas Sobre o Rural Paulista no Século 21
}

\author{
Natália Belmonte Demétrio ${ }^{1}$ \\ Rosana Baeninger ${ }^{2}$
}

\section{Resumo}

Esse trabalho tem por objetivo analisar a dinâmica de redistribuição populacional em áreas de expressiva produção agropecuária no estado de São Paulo. A partir do processo de expansão da agricultura científica e globalizada, a pesquisa discute a consolidação de variados arranjos urbanosrurais regionais no interior paulista, estruturados na interface entre o circuito espacial produtivo de distintas commodities e a mobilidade espacial da população. Tendo em vista a centralidade da produção de laranja, cana-de-açúcar e da pecuária de corte no estado, o artigo restringe a análise dos arranjos formados no entorno desses três segmentos. O Censo Demográfico de 2010 e o Censo Agropecuário de 2006 constituem as principais fontes de informação utilizadas. Ao longo da discussão, reitera-se as potencialidades dessa proposição teórica e metodológica na apreensão das recomposições das hierarquias socioespaciais e dos múltiplos espaços da migração no tecido urbanorural regional.

Palavras-chave: população rural, urbanização, globalização, regionalização

\footnotetext{
1 Doutora em Demografia pelo do Instituto de Filosofia e Ciências Humanas (IFCH/Unicamp). Integrante do Observatório das Migrações em São Paulo (CNPq/FAPESP). E-mail de contato: natalia@ @epo.unicamp.br.

${ }^{2}$ Professora do Programa de Pós-Graduação em Demografia e do Programa de Pós-Graduação em Sociologia do Instituto de Filosofia e Ciências Humanas. Pesquisadora do Núcleo de Estudos de População "Elza Berquó" (Nepo/Unicamp). Coordenadora do Projeto Temático Observatório das Migrações em São Paulo (CNPq/FAPESP). E-mail de contato: baeninger@nepo.unicamp.br
} 


\section{Introdução}

As raízes históricas do processo de urbanização em São Paulo (GONÇALVES, 1998) está na base da formação de diferentes espaços transnacionais (SASSEN, 1998) na hierarquia da rede urbana paulista. A fluidez garantida primeiramente pelas ferrovias, depois pelas rodovias e, mais recentemente, pela telemática, possibilitou a criação de um verdadeiro exército de reserva de lugares (SANTOS, 1993) para a alocação do capital transnacional, que vai desde o turismo, a indústria mais intensiva em ciência e tecnologia, os serviços especializados, até a produção agropecuária (SASSEN, 1998; ELIAS, 2003). Nesse trabalho, o enfoque recai nos processos de redistribuição de população em áreas de expressiva produção/processamento de commodities.

O reforço ao modelo agroexportador de desenvolvimento (CANALES; CANALES, 2013; CANO, 2011; BRANDÃO, 2007) e expansão da agricultura científica e globalizada (ELIAS, 2003), imprime uma nova dinâmica regional no interior paulista, com fortalecimento de eixos de expansão fora das regiões metropolitanas tradicionais (BAENINGER; OJIMA, 2008). As recomposições das hierarquias que tradicionalmente acomodaram os processos de redistribuição de população (BAENINGER, 2012) tornam insuficientes as análises da dinâmica de modernização agrícola apenas pelo viés dos fatores de expulsão e mudança (SINGER, 1980). Ao lado de tendências históricas, temse novos processos: a emergência de um novo rural (SILVA, 1999), as migrações permanentemente temporárias (SILVA, 1999b), a rotatividade migratória, a imigração com origem metropolitana, a interiorização da migração nordestina, outros espaços catalizadores da migração intra-regional (BAENINGER, 2012).

O emaranhado de escalas (BRANDÃO, 2007) que representa esses diferentes espaços da migração (BAENINGER, 1999) contribuem à formação de múltiplos arranjos na rede de cidades (MOURA, 2009). Essas formas regionais rompem com as "fronteiras disciplinares e as barreiras espaço-temporais que protegiam os ritmos" das regionalizações tradicionais (RIBEIRO, 2009, p.196), representando um desafio aos estudos sobre redistribuição de população e urbanização. É nesse sentido que Baeninger e Ojima (2008, p.132) discutem os limites das regionalizações políticoadministrativas, destacando a necessidade de identificação de espacialidades que façam "sentido não apenas do ponto de vista da correlação de forças políticas, mas que incorpore as dimensões sociais, econômicas e demográficas" (BAENINGER; OJIMA, 2008, p.132). No propósito de melhor apreender as expressões locais e regionais do processo de globalização da agricultura (ELIAS, 2003), esse trabalho apresenta o conceito de arranjo urbano-rural regional.

Para essa pesquisa, foram selecionados três circuitos espaciais produtivos (CASTILLO; FREDERICO, 2010): sucroenergético, citrícola e de carne bovina. As duas primeiras commodities representam os principais produtos agrícolas do Estado de São Paulo. Amplamente beneficiadas pela 
modernização agrícola dos anos 1970, e com forte inserção no mercado global, cana e laranja estão entre os exemplos de complexos agroindustriais (DELGADO, 1985) com maior densidade de vínculos entre agricultura e indústria processadora, com articulação de cidades do agronegócio especializadas no atendimento das demandas de seus respectivos setores (ELIAS, 2003). Já a pecuária destaca-se por apresentar uma trajetória inconstante de inserção no mercado internacional e maior desarticulação entre pecuaristas e frigoríficos (BINI, 2010). Segundo esse autor, a existência de uma série de matadouros dispersos em território estadual viabiliza a comercialização direta entre pecuaristas menos capitalizados e açougues locais, reforçando a desigualdade que marca o circuito espacial produtivo da pecuária em São Paulo.

Organizada em seis partes principais, os dois primeiros itens reconstroem o processo de urbanização e redistribuição da população rural paulista, ao longo do século 20. Dos caminhos bandeirantes aos eixos irradiados pelas políticas nacionais de desenvolvimento do governo militar, estruturou-se a espinha dorsal em torno do qual foi articulado o mercado nacional (GONÇALVES, 1998). Em seguida, discute-se o ajustamento desse mercado diante da abertura econômica dos anos 1980 e da atuação das corporações multinacionais (SANTOS, 2013). Como expressão das transformações regionais trazidas "pelo esgotamento do nacional desenvolvimentismo", são apresentados os arranjos urbanos-rurais regionais. Por fim, as duas últimas partes dedicam-se à análise da dinâmica da população e da migração nesses três arranjos.

\section{O Rural no Contexto da Rede Urbana Paulista}

Ao longo do século 20, a dinâmica da população rural no estado de São Paulo carrega a história das hierarquias construídas no âmbito da dinâmica cafeeira de incorporação de terras (NEGRI; GONÇALVES; CANO, 1988). O deslocamento dessa fronteira agrícola impulsionou a ocupação sistemática do território estadual, definindo uma primeira divisão socioespacial do trabalho colada no tempo e espaço da expansão do complexo cafeeiro (NEGRI; GONÇALVES; CANO, 1988). Nas regiões de ocupação mais antiga (Vale do Paraíba, Baixada Santista e Grande São Paulo), o histórico de capitais gerados pelo café, a concentração de população e de infraestrutura possibilitaram a construção de um parque industrial dos mais intensivos em ciência e tecnologia (NEGRI; GONÇALVES; CANO, 1988). Segundo Tartaglia e Oliveira (1988), os altos níveis de urbanização e a baixa fertilidade do solo nessa região acabaram por reduzir a atividade agropecuária à produção de frutas, hortaliças e laticínios para abastecimento local e regional (Figura 1).

Nas zonas de ocupação madura (eixo Campinas/Ribeirão Preto), onde a fronteira agrícola também contou com expressivos níveis de capitalização, o processo de urbanização atingiu amplo grau de diversificação das forças produtivas, com importante desenvolvimento industrial, 
principalmente via Complexo Agroindustrial (CAI) (DELGADO, 1985). Em especial a partir dos anos 1970, com o movimento de desconcentração econômico-populacional à luz dos planos nacionais de desenvolvimento, a dinâmica de urbanização nesse eixo passa a ser reconfigurado pela formação de importantes aglomerações urbanas (BAENINGER, 1997). Nesse contexto, Campinas consolida-se como polo tecnológico (BAENINGER, 1996), enquanto outros municípios reforçam suas atividades industriais centradas em commodities específicas (algodão em Americana, laranja em Limeira, Matão e São Carlos, cana-de-açúcar em Ribeirão Preto e Sertãozinho) (ELIAS, 2003; TARTAGLIA; OLIVEIRA, 1988) (Figura 1).

Figura 1

Regionalização do Estado de São Paulo com base na dinâmica de incorporação de terras do complexo cafeeiro

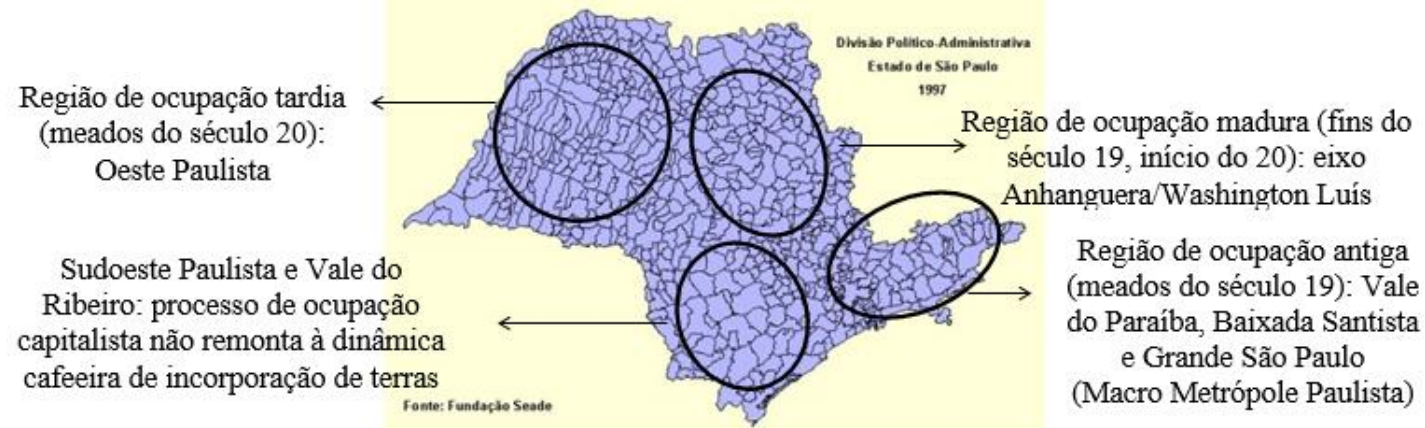

Fonte: Construído a partir das informações contidas em Negri, Gonçalves e Cano (1988).

Já nas últimas áreas de expansão do complexo cafeeiro, o processo de ocupação ocorreu de forma subordinada aos interesses do capital imobiliário e às demandas das regiões de ocupação mais consolidada (NEGRI; GONÇALVES; CANO, 1988). Nesse território, juntamente com a produção de alimentos em pequenas propriedades, as pastagens assumem grande relevância, fenômeno revelador da face mais conservadora das fronteiras agrícolas brasileiras (CHAIA, 1980; WANDERLEY, 2011). Amplamente marginalizado pela modernização agrícola de caráter nacionaldesenvolvimentista, o Oeste Paulista assiste à expansão da agricultura de commodities apenas em anos recentes (OLIVEIRA, 2012; DEMÉTRIO, 2013; MELO, 2013).

Haja vista essa bem estabelecida divisão socioespacial do trabalho, a difusão da agricultura científica e globalizada (ELIAS, 2003) e a formação de diferentes arranjos urbanos-rurais regionais ocorre desigualmente no território. Nas regiões densamente habitadas do sudeste paulista, de ocupação antiga, as "novas" atividades agrícolas (SILVA, 1999a), a expansão urbana (MOURA, 2009) e a dinâmica de periferização da população (BAENINGER, 1997) reforçam as escalas locais e regionais dos processos de redistribuição da população rural. No sudoeste do estado, as restrições sócio ambientais também dificultam a expansão da produção de commodities ligadas às cadeias globais de valor. É, portanto, no Oeste Paulista e sobretudo na porção nordeste (eixo 
Campinas/Ribeirão Preto), onde a emergência de espaços transnacionais (SASSEN, 1998) agrários ocorre com mais vigor.

\section{A evolução da população rural em São Paulo}

Como parte de um processo de transformação social mais amplo, a evolução da população pode servir à construção de uma periodização da própria dinâmica de acumulação capitalista (RENNER; PATARRA, 1980; BALÁN, 1973). Nesse sentido, o Gráfico 1 apresenta o volume de população total no estado de São Paulo, de 1872 (ano de realização do primeiro censo no Brasil) até 2010. São identificados três regimes de acumulação (HARVEY, 1992): o período agroexportador cafeeiro, no qual a produção de riqueza provinha principalmente da produção de commodities, porém não organizada segundo parâmetros globalizados de qualidade e custo ${ }^{3}$ (SANTOS, 2013); a industrialização nacional desenvolvimentista, cuja fonte principal de acumulação pautava-se na transformação de bens primários e manufaturas, "acrescentando-lhes valor pelo trabalho" (GONÇALVES, 1998, p.36); e a globalização, período no qual o crescente déficit público amplia o protagonismo dos investimentos privados no financiamento da produção, alavancando os processos de financeirização e a hegemonia do capital financeiro (SANTOS, 2013; BRANDÃO, 2007; SASSEN, 1998).

Essas diferentes fases da acumulação de capital associa-se a distintos processos de redistribuição de população (RENNER; PATARRA, 1980). O período agroexportador cafeeiro corresponde à formação do mercado de trabalho assalariado, a partir da imigração internacional (HALL, 2003; Gráfico 1). Além da dimensão étnica (SEYFERTH, 2002), o apelo à importação de força-de-trabalho manifestou uma clara estratégia de rebaixamento dos salários que a migração interna, por si só, não daria conta de proporcionar (HALL, 2003). De acordo com Gonçalves (1998, p.130), "entre 1887 e 1900, período de alta do preço do café e de grande expansão da produção, entraram em São Paulo cerca de 863 mil imigrantes". Esse contingente populacional permitiu o desenvolvimento da economia cafeeira, o adensamento das pontas da rede urbana, além de potencializar os processos de urbanização e industrialização de meados do século 20 (BALÁN, 1973).

A transição para a industrialização representou uma inflexão de tendências quanto à dinâmica de redistribuição de população. Se no período mercantil cafeeiro, o processo de urbanização desenvolveu-se à custa da ramificação da rede de cidades, no nacional desenvolvimentismo, predominou a lógica da concentração (GONÇALVES, 1998). Para Gonçalves (1998), o sistema urbano, antes estruturado para fora, interligando as diferentes cidades ao circuito internacional de

\footnotetext{
${ }^{3}$ Segundo Santos (2013), a estruturação de circuitos espaciais produtivos globalizados representa um fenômeno dos anos 1980. Até então, faltavam as condições técnicas necessárias “à unificação do espaço em termos globais e à unificação do tempo em termos globais" (SANTOS, 2013, p.40).
} 
mercadorias, passou a voltar-se também para dentro. A fluidez gerada pelas ferrovias passou a ser insuficiente à circulação de mercadorias e pessoas. Sobretudo entre 1950/1960, inicia-se um ousado projeto estatal de ampliação da malha rodoviária, modernização dos Correios, difusão do telefone e outras formas de transmissão de mensagens (SANTOS, 1992). Essa maior mobilidade, conjugada às transformações desencadeadas pela modernização agrícola (MÜLLER, 1985), impulsionou o processo de transição urbana e concentração da população nos estratos superiores da rede de cidades (MARTINE; McGRANAHAN, 2010).

\section{Gráfico 1}

Evolução da população total

Estado de São Paulo - 1872 a 2010

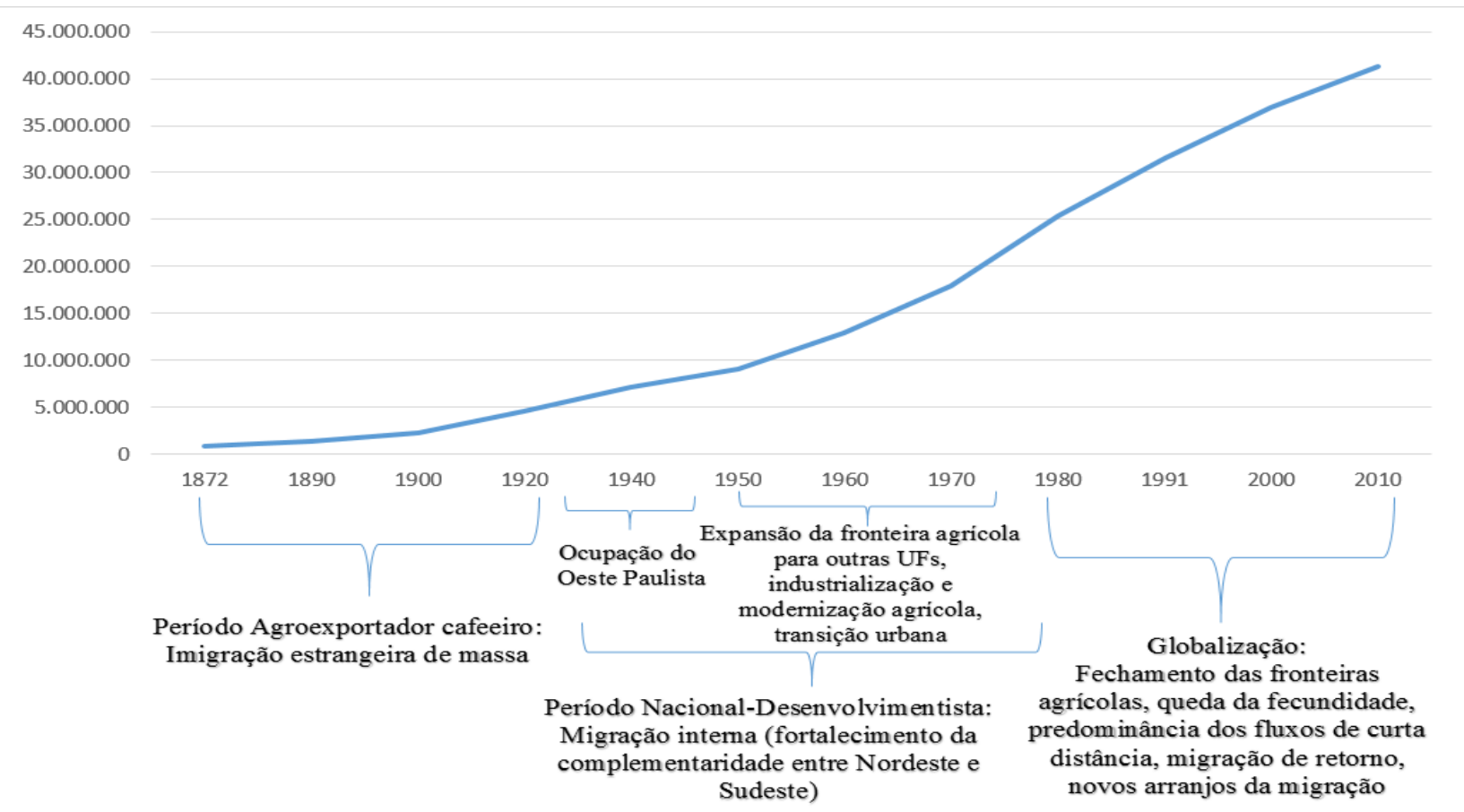

Fonte: FIBGE, Séries e Estatísticas Históricas. Disponível em: http://seriesestatisticas.ibge.gov.br. Acesso: 12/01/2017.

Entre 1920/1950, a tendência à concentração populacional foi equilibrada pelos efeitos centrífugos da expansão da fronteira agrícola rumo ao Oeste Paulista (MARTINE, 1990). Também a inexistência de um setor de bens de capital no país restringiu as transformações estruturais na agropecuária (MÜLLER, 1985). Nesse contexto, o grau de urbanização do Estado permaneceu a níveis relativamente baixos (na casa dos 50\%) (Tabela 1), com taxas de crescimento da população rural ainda positiva, embora decrescente (Tabela 2). Somente ao final da década de 1950, com a instalação de uma indústria de base, foi criada as condições concretas para a acumulação ampliada a partir da indústria (NEGRI; GONÇALVES; CANO, 1988). Ao prover máquinas, equipamentos, insumos químicos e biológicos para a agricultura (tecnologias poupadoras de força-de-trabalho), a indústria nacional abriu caminhos para transformação "generalizada de todo o sistema urbano, desenvolvendo ao extremo aquilo que [...] era ainda embrionário: a exacerbação do crescimento das 
cidades, o esvaziamento do campo e a consagração do consumo industrializado" (NEGRI; GONÇALVES; CANO, 1988, p.12) .

Tabela 1

Evolução da população total, urbana e rural, grau de urbanização e densidade demográfica (pop./Km²)

Estado de São Paulo

$1920,1940,1950,1960,1970,1980,1991,2000$ e 2010

\begin{tabular}{cccccc}
\hline Ano & População total & População urbana & População rural & Grau de urbanização Densidade demográfica \\
\hline 1920 & 4.592 .188 &.. &.. &. & 18,5 \\
1940 & 7.180 .316 & 4.012 .205 & 3.168 .111 & 55,88 & 28,93 \\
1950 & 9.134 .423 & 4.804 .211 & 4.330 .212 & 52,59 & 36,81 \\
1960 & 12.974 .699 & 8.149 .979 & 4.824 .720 & 62,81 & 52,28 \\
1970 & 17.770 .975 & 14.277 .802 & 3.493 .173 & 80,34 & 72,36 \\
1980 & 25.042 .074 & 22.196 .896 & 2.845 .178 & 88,64 & 102,25 \\
1991 & 31.588 .925 & 29.314 .861 & 2.274 .064 & 92,80 & 127,11 \\
2000 & 37.032 .403 & 34.592 .851 & 2.439 .552 & 93,41 & 148,96 \\
2010 & 41.262 .199 & 39.585 .251 & 1.676 .948 & 95,94 & 166,25 \\
\hline
\end{tabular}

Fonte: FIBGE, Censos Demográficos de 1920, 1940, 1950, 1960, 1970, 1980, 1991, 2000 e 2010

Nota: *No Censo de 1920, não havia quesito de situação de domicílio

**Não houve censo em 1930

Tabela 2

Taxa de crescimento geométrica da população total, urbana e rural (em \% a.a.)

Estado de São Paulo

1920/1940, 1940/1950, 1950/1960, 1960/1970, 1970/1980, 1980/1991, 1991/2000, 2000/2010

\begin{tabular}{lccc}
\hline \multicolumn{1}{c}{ Período } & População total & População urbana & População rural \\
\hline $1920 / 1940$ & 2,26 &.. &. \\
$1940 / 1950$ & 2,44 & 1,82 & 3,17 \\
$1950 / 1960$ & 3,57 & 5,43 & 1,09 \\
$1960 / 1970$ & 3,20 & 5,77 & $-3,18$ \\
$1970 / 1980$ & 3,49 & 4,51 & $-2,03$ \\
$1980 / 1991$ & 2,13 & 2,56 & $-2,02$ \\
$1991 / 2000$ & 1,78 & 1,86 & 0,78 \\
$2000 / 2010$ & 1,09 & 1,36 & $-3,68$ \\
\hline
\end{tabular}

Fonte: FIBGE, Censos Demográficos de 1920, 1940, 1950, 1960, 1970, 1980, 1991, 2000 e 2010

Nota: *No Censo de 1920, não havia quesito de situação de domicílio

**Não houve censo em 1930

À luz dessas mudanças estruturais, o grau de urbanização salta de 52\%, em 1950, para 88\%, em 1980, enquanto a densidade demográfica quase triplica (Tabela 1). As altíssimas taxas de crescimento da população urbana contrastam com o decrescimento da população rural que, entre 1960/1970, chega a diminuir inclusive em termos absolutos (Tabelas 1 e 2). Para Silva (1999b, p.63), nesse decênio, "foram expulsos 2,5 milhões de pessoas do campo paulista". Ao mesmo tempo em que reduziu drasticamente os postos de trabalho no setor primário, a industrialização da agricultura reforçou sua sazonalidade (MÜLLER, 1985). Surge, então, o "bóia-fria, trabalhador agrícola volante, de residência urbana" (SILVA, 1999b, p.66). Estes postos de trabalho precários e instáveis foram ocupados principalmente camponeses expropriados, sobretudo paranaenses, mineiros e nordestinos cujas terras tornaram-se alvo da especulação imobiliária no âmbito da expansão da fronteira agrícola

\footnotetext{
${ }^{4}$ Müller (1985) menciona também a centralidade da criação do Sistema Nacional de Crédito Rural no fortalecimento dos vínculos entre agricultura e indústria. Para o autor, não fosse o crédito público subsidiado, a difusão de tais tecnologias não teria sido tão intensa.
} 
nessas regiões (SILVA, 1999b). A partir dessa maior complementaridade Sudeste/Nordeste, as migrações internas de longa distância despontam-se como a principal componente da dinâmica populacional desse período ${ }^{5}$ (BAENINGER, 2012).

A década de 1980 representa outro momento de inflexão de tendências (SAWYER; RIGOTTI, 2002; MARTINE, 1990). Em primeiro lugar, a redução da fecundidade levou à estabilização do crescimento (Tabela 2). Em paralelo, verifica-se desaceleração do processo de concentração populacional nos grandes centros. Ao lado do crescimento mais acelerado das cidades médias, o censo de 1991 registrou saldo migratório negativo em mais de 400.000 mil pessoas para o município de São Paulo, centro gravitacional da indústria e das finanças no país (SAWYER; RIGOTTI, 2002). Vale destacar também o virtual fechamento da fronteira agrícola ao pequeno produtor, fenômeno que, durante o auge da modernização agrícola dos anos 1970, acomodou os problemas decorrentes da concentração fundiária e expulsão de trabalhadores do campo $^{6}$ (MARTINE, 1990; SAWYER; RIGOTTI, 2001).

De acordo com Baeninger (2012), a inovação tecnológica, conjugada ao quadro da reestruturação da produção, consolidou uma situação de desemprego estrutural e flexibilização das relações de trabalho que desencadearam uma nova configuração aos processos de mobilidade espacial da população: a rotatividade migratória. Ao criar um mercado de trabalho competitivo e instável, a nova fase do desenvolvimento capitalista retém somente a menor parte dos migrantes: os qualificados. Para a autora, essa situação traz um dos mais inquietantes desafios aos estudos migratórios: o fim do "paradigma explicativo da emigração como um dos efeitos sociais negativos do menor crescimento econômico e, sobretudo, da ausência de atividades industriais fortes" (BAENINGER, 2005, p.90). Essa dinâmica da população mais fluida, juntamente com todas as formas de fragmentação do espaço resultantes do processo de urbanização corporativa (SANTOS, 1993), reproduz um modelo espraiado de expansão geográfica da cidade, entremeado de vazios urbanos, com forte apoio do sistema rodoviário (MOURA, 2009). Sobretudo nas regiões metropolitanas, o processo de periferização da população afetou diretamente a diversificação dos movimentos intraurbanos, a intensificação da migração entre áreas periféricas e dos deslocamentos pendulares, com formas inéditas de uso e ocupação desses espaços rurais (BAENINGER, 1997).

Seja pelos problemas de classificação de situação de domicílio (RODRIGUES, 2001), seja em função da emergência de um novo rural (SILVA, 1999), tem-se um redirecionamento dos fluxos migratórios de determinadas localidades rurais, influenciados principalmente pela mobilidade

\footnotetext{
${ }^{5}$ Vale destacar também o peso do crescimento vegetativo, resultado da combinação entre taxas de fecundidade altas com níveis de mortalidade decrescentes (SAWYER; RIGOTTI, 2002).

${ }^{6}$ Martine (1990) cita os de projeto de colonização no Centro-Oeste, entre 1960/1970, como programa estatal de ocupação de novas áreas que também funcionou como válvula de escape aos conflitos fundiários.
} 
exercida pela população de alta e média renda (SAWYER; RIGOTTI, 2001). Para Favareto (2007), a incorporação de novos habitantes e novas funções à ruralidade contemporânea levaram à necessidade de outros arcabouços teóricos e metodológicos para os estudos rurais. $\mathrm{O}$ autor destaca a centralidade da abordagem territorial, perspectiva que além de reconstruir o rural como estrutura socioespacial heterogênea, reforça o desenvolvimento rural vis-à-vis ao desenvolvimento urbano (FAVARETO, 2007). Segundo Kulcsár e Curtis (2012), se as relações rurais-urbanas, até a década de 1970, eram tratadas pelo viés da industrialização, a partir de 1980/1990, a ênfase recai na diversidade regional em termos de composição demográfica e características ambientais, econômicas, culturais e histórica de cada localidade.

Na interpretação de Riella e Mascheroni (2006), as dinâmicas de globalização conduzem a uma ruralidade mais complexa e ambígua, na medida em que se verifica tanto a recuperação demográfica de determinadas regiões rurais, quanto o aprofundamento de processos de desertificação social de outras áreas. Se a formação dos mercados globais aprofunda a desarticulação dos sistemas agroalimentares regionais e nacionais, impulsionando a especialização produtiva; as facilidades de comunicação e transporte influenciaram na mais intensa integração entre os mercados, com determinadas localidades rurais registrando inclusive maior tendência à diferenciação social e à pluriatividade (RIELLA; MASCHERONI, 2006). Nesse contexto, enquanto algumas regiões rurais desenvolverão formas de reprodução social mais sustentáveis, outras áreas padecerão, cada vez mais, com a degradação ambiental, a especialização produtiva e a evasão de população do campo associada à expansão das commodities (RIELLA; MASCHERONI, 2006). Para Kulcsár e Curtis (2012), essas diferentes estruturas socioespaciais rurais combinam formas de reprodução da população que perpassam dinâmicas demográficas distintas.

É importante esclarecer que o reforço à articulação de múltiplas ruralidades (FAVARETO, 2007) demanda pesquisas que, tendo em vista as condições de produção historicamente situadas de cada região (HARVEY, 1992), posicionem essas diferentes estruturas socioespaciais na hierarquia da rede urbana (CORRÊA, 1994). Como expressão socioespacial da globalização da produção agropecuária (ELIAS, 2003), espaços transnacionais (SASSEN, 1998) cujos vínculos globais mais fortes remetem à produção de bens primários, é proposto o conceito de arranjo urbano-rural regional. Tais espacialidades têm no rural dos complexos agroindustriais seu núcleo duro, espalhando-se em tentáculos subjacentes pelo Oeste Paulista. Ou seja, representam formações regionais cujas rugosidades do espaço (SANTOS, 2002) permitiram essa nova forma de produção agropecuária (ELIAS, 2003). 


\section{Globalização da agricultura, urbanização e regionalização}

A emergência da agricultura científica e globalizada (ELIAS, 2003) está intimamente associada à consolidação de circuitos espaciais produtivos globalizados, movidos por um único conjunto motor: "a mais valia em nível mundial” (SANTOS, 1993, p.44). De acordo com Sassen (1998) e Santos (2013), as condições políticas (reformas neoliberais, abertura econômica, privatização, etc.) e tecnológicas dos anos 1970 e 1980 favoreceram o movimento de fusão e aquisição entre diferentes capitais, processo a partir do qual são formados as corporações transnacionais e os mercados globais. Dentre os grupos ligados à produção e processamento de commodities com atuação no país, Corrêa (2012) distingue tanto empresas de origem nacional (como JBS, Brasil Foods, Grupo Fisher), quanto de origem estrangeira (Bunge, ADM, Louis Dreyfus, Cargil). Com uma estratégia de atuação voltada à valorização do capital financeiro globalizado (SASSEN, 1998) e à menor materialização possível de qualquer tipo de fluxo, essas empresas globais apresentam uma dinâmica espacial que, apesar de conter certa dimensão territorial por explorarem recursos de áreas concretas, é também desterritorial pelo não compromisso com o lugar (REBORATTI, 2003).

Ao discutir as espacialidades criadas no bojo de atuação dessas corporações, Reboratti (2003) apresenta o conceito de territórios da globalização: amálgama de formas e funções cambiantes e privadas. Cambiantes porque guiadas por uma lógica não territorial. Privadas porque tentam, por todos os meios, excluir o Estado de suas decisões estratégicas. Distante do conceito tradicional de região - um espaço contíguo, organizado por redes funcionais hierárquicas - o autor propõe a reflexão dos territórios da globalização como nós, partes e franjas de territórios concretos, unidos por um sistema de fluxos que deixa um grande espaço intersticial de territórios excluídos (REBORATTI, 2003). Os nós correspondem a localizações concretas de empresas, enquanto suas franjas representam espaços concretos mais desarticulados, que ora inserem-se no mercado global, ora são excluídos, não por causas intrínsecas, mas por lógicas externas que regem todo o sistema (REBORATTI, 2003).

Já os espaços da globalização (SANTOS, 2013; SANTOS, 1993) remetem à aceleração do processo de urbanização causada pela maior espessura do sistema urbano. Essa densidade é produzida pelo uso intensivo da ciência, tecnologia e informação na construção do território, criando as condições para uma mais complexa divisão social do trabalho. O chamado curto circuito da rede cidades, isto é, a conexão imediata entre o lugar da produção e os interesses do capital globalizado, produz uma complementaridade expandida entre os lugares, inovadora por não prescindir de contiguidade espacial. É nesse sentido que a instalação de processos globais reconfigura a hierarquia da rede urbana, com a emergência de localizações representativas de outras escalas e poderes (SANTOS, 2013). Embora estruturados segundo uma divisão socioespacial do trabalho prévia, em 
regiões cujas condições pretéritas permitem a alocação desse capital, esses espaços obedecem a parâmetros globalizados de organização do trabalho e da produção, costurados por uma solidariedade organizacional que rompem desigualdades socioespaciais historicamente construídas (SANTOS, 2013). Esse meio técnico-científico e informacional, resposta geográfica à globalização da produção, espraia-se pela rede urbana de maneira desigual, de forma contínua, dispersa ou como simples pontos, assumindo a forma de zonas luminosas, zonas opacas "e uma infinidade de situações intermediárias" (SANTOS, 2013, p.48).

Ao discutir a forma urbana característica desses processos de globalização, Moura (2009) prefere o termo arranjo ao de região ou aglomeração por sua conotação mais genérica abranger uma multiplicidade de relações e escalas. Dentre os vários tipos de arranjos que a atual fase do desenvolvimento capitalista pode criar, a autora distingue os arranjos urbanos-regionais: "uma categoria espacial ligada à urbanização contemporânea" referente "às dinâmicas territoriais inerentes aos estágios mais avançados de inserção da divisão internacional do trabalho" (MOURA, 2009, p.5). Diferenciam-se das dinâmicas metropolitanas do período 1950/1970 por representarem uma formação regional mais fragmentada, dispersa, onde a tendência de expansão da metrópole engloba uma série de localidades não inseridas nos mercados globais, produzindo espacialidades híbridas, não coesas, qualitativamente distinta das aglomerações urbanas tradicionais, mais compactas (MOURA, 2009).

Baeninger e Ojima (2008) também discutem a relação entre hierarquia urbana e dinâmica da população na globalização. De acordo com os autores, a reestruturação do espaço urbano-regional, cada vez mais difuso e fragmentado, redefinem os limites das cidades "enquanto unidade de análise unitária que pode ser apreendida em termos de centro, periferia ou região" (BAENINGER; OJIMA, 2008, p.135). Segundo os autores, "ao contrário de uma dissolução da importância regional decorrente da diluição do tempo-espaço propiciado pela globalização, as formas espaciais regionais se tornam cada vez mais centrais à vida moderna" (BAENINGER; OJIMA, 2008, p.135). No entanto, essa conformação regional deve ser compreendida no âmbito de "uma nova ordem social, econômica e política", como expressão "de uma desarticulação crescente entre as formas de reprodução do capital e a reprodução social” (BAENINGER; OJIMA, 2008, p.135).

Nesse contexto, as fronteiras político-administrativas tradicionais captam cada vez menos esses espaços "privilegiados de transformação social", onde a vida cotidiana se "articula e se reproduz" (BAENINGER; OJIMA, 2008, p.136). Desde essa perspectiva, os arranjos urbanos-rurais regionais têm por objetivo identificar espacialidades que façam "sentido não apenas do ponto de vista da correlação de forças políticas, mas que incorpore as dimensões sociais, econômicas e demográficas" (BAENINGER; OJIMA, 2008, p.131-132). Ao diluir fronteiras engessadas por redes de articulação 
políticas locais e nacionais, representam espacialidades que instigam a reflexão das diversas formas que o rural regional conecta-se ao urbano local e ao sistema de cidades transnacional (SASSEN, 1998), desconstruindo uma análise enviesada por pressupostos da dicotomia campo/cidade, metrópole/interior, centro/periferia.

\section{Dinâmica da população nos arranjos urbanos-rurais regionais}

O Mapa 1 apresenta os arranjos urbanos-rurais regionais da laranja, da cana-de-açúcar e da pecuária no Estado de São Paulo7 ${ }^{7}$ A localização dessas diferentes estruturas socioespaciais no território estadual reafirma a centralidade das condições pretéritas e das rugosidades do espaço (SANTOS, 2002) em sua composição. Ainda que a pecuária tenha passado por investimentos que a alçou em outro patamar de produção, a importância dessa atividade no Oeste Paulista remete ao caráter excludente e pouco capitalizado de sua fronteira agrícola (TARTAGLIA; OLIVEIRA, 1988). Em contrapartida, a concentração dos arranjos da cana e da laranja a nordeste do estado, região que desde o momento histórico de sua ocupação capitalista é produtora de commodities integrada ao mercado internacional, reforça ser esse o segmento com maior densidade de vínculos entre agricultura/indústria e os principais veios de disseminação da agricultura científica e globalizada (ELIAS, 2003).

\section{Mapa 1}

Arranjos urbanos-rurais regionais da laranja, cana-de-açúcar e pecuária Estado de São Paulo, segundo municípios - 2006/2010

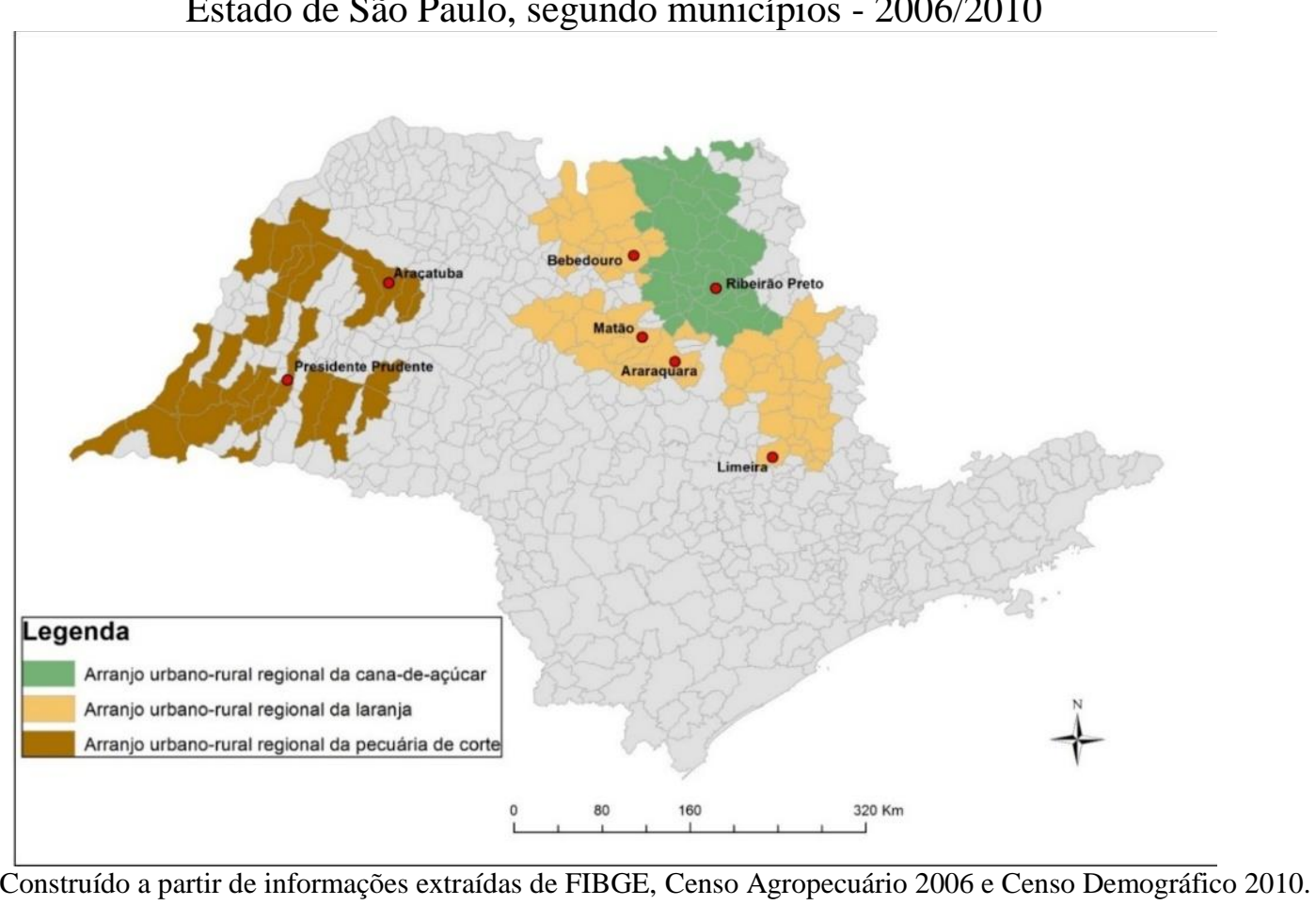

\footnotetext{
${ }^{7}$ A metodologia empregada na construção dos arranjos urbanos-rurais regionais, bem como os indicadores selecionados, encontra-se em Demétrio (2016).
} 
Seja em função de suas raízes históricas, seja devido às características intrínsecas de seus circuitos espaciais produtivos (CASTILLO; FREDERICO, 2010), esses arranjos urbanos-rurais regionais constituem espacialidades bastante heterogêneas entre si. Representam, vínculos globais de intensidade distinta, com mecanismos de desencaixe (GIDDENS, 1991) distintos. Nesse sentido, são também híbridos, desiguais, com fluidez diferenciada do espaço, do capital e da população (BAENINGER, 2012).

Com uma população superior a dois milhões de habitantes, o arranjo da laranja destaca-se pelo significativo volume populacional, inclusive em situação de domicílio rural: mas de 187 mil pessoas, em 2000, e quase 150 mil, em 2010 (Tabela 3). O arranjo urbano-rural regional da cana-de-açúcar, por sua vez, sobressai pelo baixo volume de população residente no rural - pouco mais de 40 mil pessoas, no total de quase 1,5 milhões de habitantes do arranjo - e elevado grau de urbanização: 96\%, em 2000, e 97\% em 2010, valores acima do estimado até mesmo para o conjunto do estado (Tabela 3). Essa evidência reitera o caráter eminentemente urbano da agricultura científica e globalizada (ELIAS, 2003). Por fim, o arranjo da pecuária chama atenção pelo mais baixo nível de urbanização: $90,54 \%$ em 2000, e 92,9\% em 2010. Com um total de população de cerca de um milhão de pessoas, quase 78 mil residiam em áreas classificadas como rurais em 2010 (Tabela 3).

Tabela 3

População total, urbana, rural, taxa de crescimento geométrico (em \% a.a.) e grau de urbanização (em \%) Arranjo urbano-rural regional da laranja, da cana-de-açúcar, da pecuária e Estado de São Paulo 2000 e 2010

\begin{tabular}{|c|c|c|c|c|c|c|c|c|c|c|c|}
\hline & \multicolumn{2}{|c|}{ População total } & \multicolumn{2}{|c|}{ População urbana } & \multicolumn{2}{|c|}{ População rural } & \multicolumn{2}{|c|}{ Grau de urbanização } & \multicolumn{3}{|c|}{ Taxa de crescimento } \\
\hline & 2000 & 2010 & 2000 & 2010 & 2000 & 2010 & 2000 & 2010 & Total & Urbana & Rural \\
\hline Arranjo da laranja & 2.068 .496 & 2.286 .243 & 1.880 .950 & 2.142 .591 & 187.546 & 143.652 & 90,93 & 93,72 & 1,01 & 1,31 & $-2,63$ \\
\hline Arranjo da cana-de-açúcar & 1.296 .702 & 1.509 .910 & 1.248 .069 & 1.468 .230 & 48.633 & 41.680 & 96,25 & 97,24 & 1,53 & 1,64 & $-1,53$ \\
\hline Arranjo da pecuária & 1.033 .018 & 1.097 .896 & 935.312 & 1.019 .989 & 97.706 & 77.907 & 90,54 & 92,90 & 0,61 & 0,87 & $-2,24$ \\
\hline Estado de São Paulo & 37.032 .403 & 41.262 .199 & 34.592 .851 & 39.585 .251 & 2.439 .552 & 1.676 .948 & 93,41 & 95,94 & 1,09 & 1,36 & $-3,68$ \\
\hline
\end{tabular}

Fonte: FIBGE, Censos Demográficos 2000 e 2010.

O elevado ritmo de incremento populacional do arranjo da cana - 1,53\% a.a., superior inclusive à média estimada para o conjunto do estado de São Paulo (1,09\% a.a.) e quase o triplo do verificado para o arranjo da pecuária $(0,61 \%$ a.a.) - reforça a hipótese de ser esse o espaço mais luminoso em termos de inserção nos mercados globais (SANTOS, 2013; SASSEN, 1998) (Tabela 3). A taxa negativa de crescimento da população rural para o conjunto do território paulista $(-3,68 \%$ a.a.) está associada, em grande medida, à reclassificação da situação de domicílio, em especial na capital (RODRIGUES, 2001). A despeito dessa questão, verifica-se a permanência dos fatores de expulsão (SINGER, 1980) no estado de São Paulo, compondo aquilo que Baeninger (2012) denomina de último fio do êxodo rural paulista. O ritmo menos intenso de decrescimento populacional no rural do arranjo da cana reflete a diminuição do estoque de população no campo dessa região, efeito de mais de meio século de modernização agropecuária (ELIAS, 2003; Tabela 3). 
Para melhor compreender a composição da população rural nos diferentes arranjos urbanosrurais regionais, a Tabela 4 consta a distribuição dessa população por situação de setor. Levando em consideração apenas a população residente em setores normais ou não especiais, tem-se que, no arranjo da laranja, cerca de 130 mil pessoas residem em setores rurais exclusive aglomerados (o que representa 93,9\% do total de população rural). O volume de população em setores do tipo "outros aglomerados rurais" também é digno de nota: 4.691 habitantes, enquanto no arranjo da cana é zero e no da pecuária são somente 230 pessoas (Tabela 4). O estoque de população urbana em área não urbanizada de vila ou cidade (12.282 pessoas) e em área urbana isolada (10.753) corroboram a multiplicidade de lugares rurais que compõem o arranjo da laranja (Tabela 4). O arranjo urbano-rural regional da cana-de-açúcar destaca-se por apresentar o menor percentual de população em setores rurais tradicionais (84\%) (Tabela 4). Ao mesmo tempo, é registrado importante volume de população em aglomerados rurais do tipo expansão urbana e núcleos ${ }^{8}$. Por fim, no arranjo da pecuária, quase 99\% da população rural vive em setores rurais exclusive aglomerados. Sobressai, ainda, o volume de população em áreas não urbanizadas de vila e cidade e em setores urbanos isolados, o que também reforça a miríade de tipos urbanos no tecido desse arranjo (Tabela 4).

Tabela 4

População segundo situação de setor

Arranjo urbano-rural regional da cana-de-açúcar, laranja e pecuária 2010

\begin{tabular}{|c|c|c|c|c|c|c|}
\hline \multirow{2}{*}{ Situação de setor } & \multicolumn{2}{|c|}{ Arranjo da cana } & \multicolumn{2}{|c|}{ Arranjo da laranja } & \multicolumn{2}{|c|}{ Arranjo da pecuária } \\
\hline & n & $\%$ & n & $\%$ & $\mathbf{n}$ & $\%$ \\
\hline 1. Área de vila ou cidade & 1.450 .059 & 99,5 & 2.112 .386 & 98,9 & 984.259 & 97,35 \\
\hline 2. Área não urbanizada de vila ou cidade & 4.422 & 0,3 & 12.282 & 0,6 & 12.791 & 1,27 \\
\hline 3. Área urbana isolada & 3.376 & 0,2 & 10.993 & 0,5 & 13.982 & 1,38 \\
\hline Total de população urbana & 1.457 .857 & 100,0 & 2.135 .661 & 100,0 & 1.011 .032 & 100,00 \\
\hline 4. Aglomerados rurais do tipo expansão urbana & 3.085 & 8,2 & 1.578 & 1,2 & 0 & 0,00 \\
\hline 5. Povoados & 863 & 2,3 & 2.104 & 1,6 & 588 & 0,85 \\
\hline 6. Núcleo & 2.082 & 5,5 & 212 & 0,2 & 0 & 0,00 \\
\hline 7. Outros aglomerados rurais & 0 & 0,0 & 4.691 & 3,6 & 230 & 0,33 \\
\hline 8. Zona rural exlcusive aglomerados & 31.672 & 84,0 & 121.464 & 93,4 & 68.044 & 98,81 \\
\hline Total de população rural & 37.702 & 100,0 & 130.049 & 100,0 & 68.862 & 100,00 \\
\hline
\end{tabular}

Fonte: FIBGE, Censo Demográfico 2010

Nota: Dados do universo

Por questão de sigilo, as informações em setores censitários com menos de 5 domicîlios não são divulgadas. Diante disso, as estimativas por setor censitário apresentam diferenças se comparadas às informações agregadas por municípios, por exemplo.

Não está inclú́da a população residente em setores censitários especiais, como penitenciárias, assentamentos rurais, terras indígenas, etc.

A Tabela 5 apresenta a população rural e urbana em setores censitários especiais. Na análise dessas estimativas é fundamental destacar a questão do sigilo das informações: setores com menos de cinco domicílios não têm seus dados divulgados nesse nível de desagregação (FIBGE, 2011) ${ }^{9}$. O

\footnotetext{
${ }^{8}$ Vale recuperar a definição de núcleos: “aglomerado rural vinculado a um único proprietário do solo [...], dispondo ou não dos serviços ou equipamentos definidores dos povoados" (IBGE, 2011, p.12).

${ }^{9}$ Haja vista essa limitação, faz-se importante destacar a provável subenumeração da população de assentados, sobretudo no arranjo urbano-rural regional da pecuária, cuja localização concentra inúmeros os projetos de assentamentos rurais no estado de São Paulo (DEMÉTRIO, 2016).
} 
exame dessa tabela evidencia uma dimensão importante do rural no arranjo urbano-rural regional da pecuária: a presença de penitenciárias, colônias penais e presídios. Segundo Cescon (2012), a construção dessas instituições remeteu à uma política estadual cuja finalidade, além de promover a desconcentração da população carcerária, era também aumentar o tamanho populacional de vários municípios da Alta Paulista e, com isso, ampliar os repasses dos governos estadual e federal.

Tabela 5

População residente em setores censitários especiais

Arranjo urbano-rural regional da cana-de-açúcar, laranja e pecuária, por municípios

Estado de São Paulo

2010

\begin{tabular}{|c|c|c|c|c|c|c|c|}
\hline \multirow{2}{*}{\multicolumn{2}{|c|}{ Tipo de Setor }} & \multicolumn{2}{|c|}{ Arranjo da cana } & \multicolumn{2}{|c|}{ Arranjo da laranja } & \multicolumn{2}{|c|}{ Arranjo da pecuária } \\
\hline & & & & & & & \\
\hline \multirow{8}{*}{ 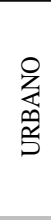 } & 1 -Setor especial de aglomerado subnormal & 14.117 & 89,85 & 2.015 & 41,1 & 601 & 8,54 \\
\hline & 2 - Setor especial quartéis, bases militares, etc. & 0 & 0,00 & 0 & 0,0 & 0 & 0,00 \\
\hline & 3 - Setor especial de alojamento, acampamentos, etc. & 0 & 0,00 & 0 & 0,0 & 11 & 0,16 \\
\hline & 4 - Setor especial de embarcações, barcos, navios, etc. & 0 & 0,00 & 0 & 0,0 & 0 & 0,00 \\
\hline & 5 - Setor especial de aldeia indígena & 0 & 0,00 & 0 & 0,0 & 0 & 0,00 \\
\hline & 6 - Setor especial de penitenciárias, colônias penais, presídios, cadeias, etc. & 378 & 2,41 & 1.518 & 31,0 & 5.343 & 75,93 \\
\hline & 7 - Setor especial de asilos, orfanatos, conventos, hospitais, etc. & 1.216 & 7,74 & 1.369 & 27,9 & 1.082 & 15,38 \\
\hline & 8 - Setor especial de projetos de assentamentos rurais & 0 & 0,00 & 0 & 0,0 & 0 & 0,00 \\
\hline \multirow{10}{*}{ 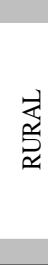 } & Total urbano & 15.711 & 100,00 & 4.902 & 100,0 & 7.037 & 100,00 \\
\hline & 1 -Setor especial de aglomerado subnormal & 0 & 0,00 & 0 & 0,00 & 0 & 0,00 \\
\hline & 2 - Setor especial quartéis, bases militares, etc. & 0 & 0,00 & 0 & 0,00 & 0 & 0,00 \\
\hline & 3 - Setor especial de alojamento, acampamentos, etc. & 0 & 0,00 & 35 & 0,99 & 2 & 0,03 \\
\hline & 4 - Setor especial de embarcações, barcos, navios, etc. & 0 & 0,00 & 0 & 0,00 & 0 & 0,00 \\
\hline & 5 - Setor especial de aldeia indígena & 0 & 0,00 & 0 & 0,00 & 0 & 0,00 \\
\hline & 6 - Setor especial de penitenciárias, colônias penais, presídios, cadeias, etc. & 6 & 9,68 & 2.084 & 59,12 & 7.623 & 99,97 \\
\hline & 7 - Setor especial de asilos, orfanatos, conventos, hospitais, etc. & 56 & 90,32 & 765 & 21,70 & 0 & 0,00 \\
\hline & 8 - Setor especial de projetos de assentamentos rurais & 0 & 0,00 & 641 & 18,18 & 0 & 0,00 \\
\hline & Total rural & 62 & 100,00 & 3.525 & 100,00 & 7.625 & 100,00 \\
\hline \multicolumn{8}{|c|}{ Fonte: FIBGE, Censo Demográfico 2010} \\
\hline & & & & & & & \\
\hline
\end{tabular}

A Tabela 6 reúne os principais indicadores que sintetizam a composição por idade e sexo da população: razão de sexo, índice de envelhecimento e razão de dependência. Com relação à população urbana, o arranjo urbano-rural regional da laranja sobressai pela maior participação dos homens no total de população, enquanto o arranjo da pecuária registra a mais baixa razão de sexo (fato que se inverte considerando a situação de domicílio rural). Para ambas as situações, o arranjo da pecuária distingue-se pelo seu mais avançado processo de envelhecimento (índice de envelhecimento igual a 72,05 no urbano e 71,77 no rural), o que reflete também em elevadas razões de dependência (51,42 no urbano e 57,98 no rural). Em contraste, o arranjo da cana-de-açúcar apresenta os mais baixos índices de envelhecimento (56,3 no urbano e 38,28 no rural), reforçando ser essa a população mais jovem dentre os casos considerados (Tabela 6).

Em linhas gerais, os indicadores apresentados reforçaram o maior dinamismo do setor sucroenergético (medido pela taxa de crescimento populacional do arranjo urbano-rural da cana-deaçúcar); a importância dos núcleos como local de residência de sua população rural, além de seu caráter extremamente jovem (índice de envelhecimento da população rural estimado em 38,28) (Tabela 5). Já o arranjo da laranja abarca significativo volume de população rural, sobremaneira concentrados em setores rurais exclusive aglomerados, mas ainda em povoados e outros aglomerados rurais. A pirâmide etária da população rural desse arranjo apresenta descontinuidades menos 
evidentes e uma razão de sexo mais equilibrada. Por fim, o arranjo da pecuária destaca-se pela taxa de crescimento mais estagnada, volume significativo de população urbana em setores não urbanizados de vila ou cidade e em áreas urbanas isoladas. Ademais, deve ser reforçado a concentração de presídios e de projetos de assentamentos (estes precariamente captados pelo censo), além de razão de sexo, razão de dependência e índice de envelhecimento elevados (estimativas referentes à população rural, desconsiderando a população carcerária).

Tabela 6

Razão de sexo, razão de dependência e índice de envelhecimento, por situação de domicílio

Arranjo urbano-rural regional da laranja, da cana-de-açúcar e da pecuária/SP

2010

\begin{tabular}{|c|c|c|c|c|}
\hline & & Razão de sexo ${ }^{1}$ & Razão de Dependência² & Índice de Envelhecimento ${ }^{3}$ \\
\hline \multirow{3}{*}{ 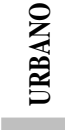 } & Arranjo da laranja & 97,10 & 49,57 & 62,6 \\
\hline & Arranjo da cana & 95,96 & 49,02 & 56,3 \\
\hline & Arranjo da pecuária & 93,35 & 51,42 & 72,05 \\
\hline & & Razão de sexo & Razão de Dependência & Índice de Envelhecimento \\
\hline \multirow{3}{*}{ 趈 } & Arranjo da laranja & 112,06 & 54,72 & 55,97 \\
\hline & Arranjo da cana & 112,36 & 53,17 & 38,28 \\
\hline & Arranjo da pecuária & 113,75 & 57,98 & 71,77 \\
\hline \multicolumn{5}{|c|}{ Fonte: FIBGE, Censo Demográfico 2010} \\
\hline \multicolumn{5}{|c|}{ Nota: Não foi considerado população carcerária } \\
\hline \multicolumn{5}{|c|}{${ }^{1}$ Razão de sexo: (homens/mulheres)*100 } \\
\hline \multicolumn{5}{|c|}{${ }^{2}$ Razão de dependência: $((0 a 4$ anos $)+(60$ anos e mais $) /(15$ a 59 ano $)) * 100$} \\
\hline \multicolumn{5}{|c|}{ 3Índice de Envelhecimento: $((60$ anos e mais $) /(0$ a 14 anos $)) * 100$} \\
\hline
\end{tabular}

\section{Migração e crescimento da população nos arranjos urbanos-rurais regionais}

A participação relativa da migração no crescimento populacional reforça o dinamismo do arranjo urbano-rural regional da cana-de-açúcar, onde mais de 40\% do crescimento demográfico deveu-se à migração, entre 2000/2010 (Tabela 7). Em contraste, no arranjo da pecuária, verifica-se permanência da tendência de esvaziamento populacional, característica comum ao Oeste Paulista desde 1950 (Tabela 7; NEGRI; GONÇALVES; CANO, 1988).

Tabela 7

Crescimento absoluto, saldo migratório anual, crescimento vegetativo e participação relativa da migração no crescimento absoluto da população $(\mathrm{em} \%)$

Arranjo urbano-rural regional da laranja, da cana-de-açúcar e da pecuária/SP $2000 / 2010$

\begin{tabular}{l|c|c|c|c|c}
\hline \multicolumn{1}{c|}{\begin{tabular}{c} 
Arranjos urbanos-rurais \\
\multicolumn{1}{c|}{ regionais }
\end{tabular}} & Crescimento Absoluto & \multicolumn{2}{|c|}{$\begin{array}{c}\text { Saldo Migratório } \\
\text { Decenal }\end{array}$} & Crescimento vegetativo & $\begin{array}{c}\text { Participação relativa da migração } \\
\text { no crescimento absoluto (em \%) }\end{array}$ \\
\hline Arranjo da laranja & 217.747 & 6.391 & 63.910 & 211.356 & 29,35 \\
Arranjo da cana-de-açúcar & 213.208 & 9.069 & 90.690 & 204.139 \\
Arranjo da pecuária & 64.878 & -175 & -1.750 & 65.053 & 42,54 \\
\hline
\end{tabular}

Fonte: FIBGE, Censo Demográfico 2000 e 2010 e Fundação Seade, Informação dos Municípios Paulistas. Disponível em: http://www.imp.seade.gov.br/frontend/\#/. Acesso 01/02/2017.

A análise dos processos migratórios interestadual, intraestadual e intra-arranjo permite identificar a articulação de diferentes complementaridades socioespaciais nos arranjos estudados. Em primeiro lugar, a Tabela 8 evidencia a centralidade no Nordeste na composição do saldo positivo tanto no arranjo da cana e da laranja, com trocas que ultrapassam 20 mil pessoas. No arranjo da pecuária, embora também apresente trocas positivas com o Nordeste, a diferença não chega a 3.000 
migrantes. Nesse arranjo, as perdas de população para o Norte e, principalmente, para o Sul e Centro-Oeste chegam mesmo a compor trocas interestaduais negativas (Tabela 8).

\begin{tabular}{|c|c|c|c|c|c|c|c|}
\hline \multicolumn{8}{|c|}{$\begin{array}{l}\text { Tabela } 8 \\
\text { Volume de emigrantes e imigrantes int } \\
\text { Arranjo urbano-rural regional da laran } \\
\text { Estado de São Paulo - 2005/2010 }\end{array}$} \\
\hline & & Norte & Nordeste & $\begin{array}{c}\text { Sudeste } \\
\text { (exceto SP) }\end{array}$ & Sul & Centro-Oeste & $\begin{array}{c}\text { Total } \\
\text { interestadual }\end{array}$ \\
\hline \multirow{4}{*}{ 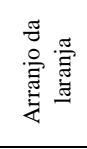 } & Imigrantes & 1.661 & 28.051 & 13.119 & 6.263 & 6.302 & 55.396 \\
\hline & Emigrantes & 1.291 & 4.678 & 9.595 & 5.868 & 4.571 & 26.003 \\
\hline & Trocas & 370 & 23.373 & 3.524 & 395 & 1.731 & 29.393 \\
\hline & IEM & 0,13 & 0,71 & 0,16 & 0,03 & 0,16 & 0,36 \\
\hline \multirow{4}{*}{ 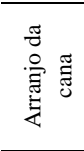 } & Imigrantes & 1.091 & 27.244 & 15.910 & 3.661 & 4.137 & 52.043 \\
\hline & Emigrantes & 618 & 5.599 & 10.221 & 3.164 & 5.382 & 24.984 \\
\hline & Trocas & 473 & 21.645 & 5.689 & 497 & -1.245 & 27.059 \\
\hline & IEM & 0,28 & 0,66 & 0,22 & 0,07 & $-0,13$ & 0,35 \\
\hline \multirow{4}{*}{ 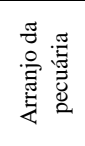 } & Imigrantes & 776 & 4.262 & 2.323 & 5.843 & 7.478 & 20.682 \\
\hline & Emigrantes & 927 & 1.410 & 1.759 & 7.884 & 10.142 & 22.122 \\
\hline & Trocas & -151 & 2.852 & 564 & -2.041 & -2.664 & -1.440 \\
\hline & IEM & $-0,09$ & 0,50 & 0,14 & $-0,15$ & $-0,15$ & $-0,03$ \\
\hline
\end{tabular}

Em nível intraestadual, os três arranjos despontam-se como áreas de absorção da população da Região Metropolitana de São Paulo (sobretudo o arranjo urbano-rural regional da laranja) e rotatividade migratória com o interior (Tabela 9), o que expressa a reconfiguração da relação migração/desenvolvimento (BAENINGER, 2012). Vale ressaltar que apenas o arranjo da cana-deaçúcar apresenta trocas positivas com os demais municípios do interior paulista (Tabela 9).

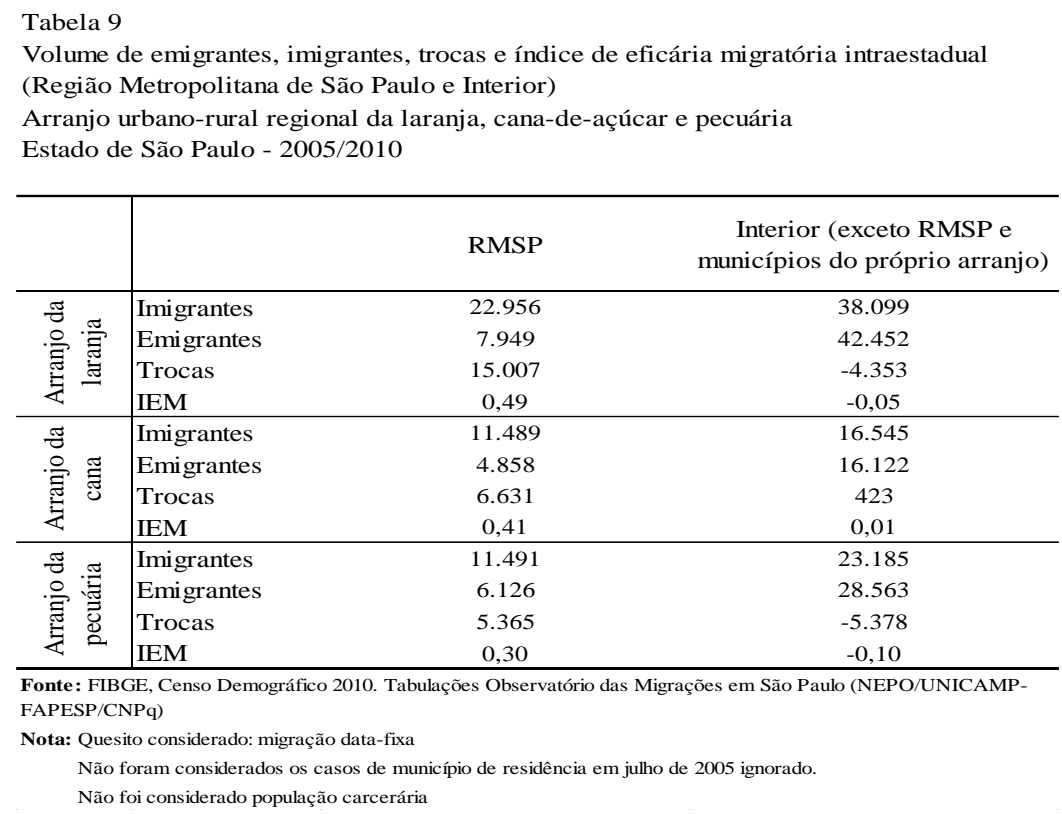

Considerando somente as principais cidades de cada arranjo urbano-rural regional, a condição de rotatividade migratória também sugere as redefinições das complementaridades regionais e a produção de outras escalas da migração não coincidentes com as hierarquias urbanas tradicionais (Tabela 10; BAENINGER, 2012). Exceção feita a Araraquara, cujo índice de eficácia migratória de 
0,47 identifica relativa capacidade de absorção da população do próprio arranjo, todas as demais localidades apresentam IEM muito próximo a zero ou mesmo negativo. Embora permaneçam com altos volumes imigratórios (o que reforça a permanência de processos históricos desses municípios como capitais regionais) (BAENINGER, 2005), a coexistência de altos volumes emigratórios revela a redefinição dos fatores de expulsão, tradicionalmente associados aos processos de mudança ou estagnação (SINGER, 1980).

\section{Tabela 10}

Volume de emigrantes, imigrantes, trocas de população e índice de eficária migratório intra-arranjo urbano-rural regional Municípios de Limeira, Araraquara, Bebedouro, Ribeirão Preto, Araçatuba e Presidente Prudente

Estado de São Paulo - 2005/2010

\begin{tabular}{|c|c|c|c|c|}
\hline Municípios & Imigrantes & Emigrantes & Trocas & IEM \\
\hline Limeira & 846 & 763 & 83 & 0,05 \\
\hline Araraquara & 2.132 & 766 & 1.366 & 0,47 \\
\hline Bebedouro & 638 & 1.061 & -423 & $-0,25$ \\
\hline Ribeirão Preto & 6.804 & 5.661 & 1.143 & 0,09 \\
\hline Araçatuba & 1.421 & 1.506 & -85 & $-0,03$ \\
\hline Presidente Prudente & 3.872 & 3.091 & 781 & 0,11 \\
\hline
\end{tabular}

Em linhas gerais, no arranjo da laranja, as trocas altamente positivas com a RMSP e as demais UFs - em especial na sub-região de Limeira - equilibraram os efeitos da perda de população para o interior do Estado. Como resultado, tem-se um crescimento próximo a 1\% a.a. (Tabela 11). Já o arranjo da cana-de-açúcar distingue-se por ganhar população tanto da RMSP, como do interior e de outras unidades da federação, o que influencia seu mais acelerado ritmo de crescimento (1,5\% a.a.). Por fim, o arranjo da pecuária apresenta saldo positivo apenas com as trocas estabelecidas com a RMSP. Daí seu crescimento estagnado em 0,56\% a.a. (Tabela 11). Além de reiterar a metrópole de São Paulo como espaço perdedor de população (BAENINGER, 1999) para quase todos os municípios dos arranjos, essa investigação evidenciou a centralidade da imigração nordestina na definição do ritmo de crescimento populacional dessas espacialidades (vide Tabelas 8 e 9).

Tabela 11

Taxa geométrica da população total (em \% a.a.), saldo migratório interestadual e intraestuadal (Região Metropolitana de São Paulo e interior)

Arranjo urbano-rural regional da laranja, da cana-de-açúcar e da pecuária/SP 2000/2010

\begin{tabular}{|c|c|c|c|c|}
\hline $\begin{array}{c}\text { Arranjos urbanos-rurais } \\
\text { regionais }\end{array}$ & $\begin{array}{c}\text { Taxa geométrica de crescimento } \\
\text { da população total (em \% a.a.) } \\
\text { (entre } 2000 \text { e 2010) }\end{array}$ & $\begin{array}{l}\text { Saldo migratório } \\
\text { interestadual } \\
\text { (data-fixa) }\end{array}$ & $\begin{array}{l}\text { Saldo intraestadual } \\
\text { (RMSP) } \\
\text { (data-fixa) }\end{array}$ & $\begin{array}{l}\text { Saldo intraestadual } \\
\text { (interior) } \\
\text { (data-fixa) }\end{array}$ \\
\hline Arranjo da laranja & 1,02 & 29.393 & 15.007 & -4.353 \\
\hline Sub-região Limeira & 1,15 & 14.514 & 9.445 & -293 \\
\hline Sub-região Matão/Araraquara & 1,02 & 10.635 & 2.845 & -754 \\
\hline Sub-região Bebedouro & 0,64 & 4.244 & 2.717 & -3.306 \\
\hline Arranjo da cana-de-açúcar & 1,50 & 27.059 & 6.631 & 386 \\
\hline Arranjo da pecuária & 0,56 & -1.440 & 5.365 & -5.378 \\
\hline
\end{tabular}

Fonte: FIBGE, Censo Demográfico 2010. Tabulações Observatório das Migrações em São Paulo (NEPO/UNICAMP-FAPESP/CNPq).

Nota: Não foi considerado população carcerária

Não foram considerados os casos de município de residência em julho de 2005 ignorado.

Os pequenos números apresentam distorções em função da expansão da amostra. Por essa razão, são apresentados enquantos indicadores de tendências. 


\section{Considerações finais}

A recomposição do processo de redistribuição da população rural em São Paulo, à luz da hierarquia da rede urbana, permitiu articular, em diferentes momentos históricos, o campo à cidade, segundo variados recortes espaciais, propondo debates sobre região e lugar, redes e escalas (SANTOS, 2002). Como expressão socioespacial e demográfica da globalização da agropecuária (ELIAS, 2003), são apresentados os arranjos urbanos-rurais regionais, estruturados na interface entre dinâmica da população e circuitos espaciais produtivos da produção (CASTILLO; FREDERICO, 2010). No caso dos arranjos urbanos-rurais regionais de estudo, os setores citrícola, sucroenergético e de frigoríficos representam as redes principais que conduzem a inserção dessas espacialidades nos mercados globais, processo cuja análise envolve desde as raízes históricas da região, a incidência de políticas públicas, até o papel desempenhado pelas elites locais (OLIVEIRA; 2012; BINI, 2014; BRANDÃO, 2007).

A despeito de esses três arranjos apresentarem dinâmicas de redistribuição de população que apontam os desencaixes característicos dos processos de globalização (GIDDENS, 1991; BAENINGER, 2012), é possível distinguir diferentes níveis de inserção global dessas espacialidades, com formas de fragmentação do território (SANTOS, 2013) mais ou menos intensas. O caso da laranja, por exemplo, é revelar de vínculos globais de intensidade intermediária. Com uma produção agrícola historicamente voltada ao mercado externo e um processo de urbanização que remonta ao início do século 19, esse arranjo contou com tempo e espaço para articulação de um mercado consumidor integrado (NEGRI; GONÇALVES; CANO, 1988), dinamizado por importantes cidades médias imersas, inclusive, em dinâmicas metropolitanas. Nesse cenário, os processos de redistribuição de sua população rural conjugam as novas atividades agrícolas (SILVA, 1999), os problemas de classificação de situação de domicílio (RODRIGUES, 2001) e os fenômenos relativos ao circuito espacial produtivo da citricultura (MAZZALI, 2000; ELIAS, 2003; CASTILLO; FREDERICO, 2010).

Já o arranjo urbano-rural regional da cana-de-açúcar destaca-se como o espaço mais luminoso em termos de inserção global. O protagonismo das corporações multinacionais de origem estrangeira (CORRÊA, 2012), combinadas às características intrínsecas ao setor sucroenergético (CASTILLO, 2015) e às raízes da urbanização na porção nordeste do Estado (GONÇALVES, 1998), produz uma cadeia produtiva das mais integradas e coordenadas. Acompanhando os desencaixes e fragmentação do espaço, tem-se forte incentivo à especialização produtiva, concentração fundiária e grande vulnerabilidade do lugar às oscilações do mercado (CASTILLO, 2015). Por fim, o arranjo da pecuária sobressai pela maior desarticulação entre produtores (pecuaristas) e indústria processadora (frigoríficos), com a possibilidade de comercialização direta com açougues locais contribuindo à 
conformação de vínculos globais mais truncados (BINI, 2010). Ao lado da agroindústria de abate de alto padrão tecnológico e com forte entrada nas grandes redes atacadistas e varejistas, verifica-se a permanência de uma criação de bovinos mais tradicional, de baixa inovação, voltada aos mercados regionais. No Estado de São Paulo, a valorização do preço da terra trazida pela expansão da agricultura científica e globalizada (ELIAS, 2003) tem provocado o paulatino deslocamento do circuito superior desse segmento para fora do território estadual (BINI, 2010). Ao mesmo tempo, a incidência de políticas públicas e a dinâmica de urbanização no Oeste Paulista, composta majoritariamente por pequenos municípios, o comércio de alimentos não integrado às cadeias globais é mais forte. Nesse cenário, a resistência de uma população sitiante (MELO, 2013), com entrada no sistema agroalimentar regional (SANT'ANA et al, 2013), coloca entraves à expansão desenfreada das commodities, reforçando solidariedades orgânicas que se contrapõem à tendência de fragmentação do território (SANTOS, 2013).

\section{Referências Bibliográficas}

BAENINGER, R. Espaço e tempo em Campinas: migrantes e a expansão do polo industrial paulista. Campinas: CMU/UNICAMP, 1996.

BAENINGER, R. Deslocamentos populacionais, urbanização e regionalização. In: Anais do I Encontro Nacional sobre Migração. Curitiba, 12 a 14 de novembro de 1997.

BAENINGER, R. Região, Metrópole e Interior: espaços ganhadores e espaços perdedores nas migrações recentes no Brasil - 1980/1996. (Tese de Doutorado) - Campinas-SP, IFCH - UNICAMP, 1999.

BAENINGER, R. São Paulo e suas migrações no final do século XX. São Paulo em Perspectiva, v.19, n.3, p.84-96, jul./set. 2005.

BAENINGER, R. Fases e faces da migração em São Paulo. Campinas: Núcleo de Estudos de População NEPO/UNICAMP, 2012.

BAENINGER, R.; OJIMA, R. Novas territorialidades e a sociedade de risco: evidências empíricas e desafios teóricos para a compreensão dos novos espaços da migração. Papeles de Población, v.58, p.141-154, 2008.

BINI, D. L. de C. Mudanças na pecuária de corte e algumas implicações sócio-espaciais na Região de Araçatuba (SP). Revista Formação, n.16, v.2, 2010.

BRANDÃO, C. A. Território e desenvolvimento: as múltiplas escalas entre o local e o global. Campinas, Editora da UNICAMP, 2007.

CAMARANO, A. A; ABRAMOVAY, R. Êxodo rural, envelhecimento e masculinização no Brasil: panorama dos últimos cinquenta anos. In: Encontro Anual da Associação Nacional de Pós-Graduação em Ciências Sociais. Caxambu: ANPOCS, 1997.

CANALES, A.; CANALES, M. De la metropolización a las agrópolis: el nuevo poblamiento urbano en el Chile actual. Polis, julio 2013.

CANO, W. Novas determinações sobre as questões regional e urbana após 1980. Texto para Discussão. Campinas: IE/UNICAMP, n.193, p.1-36, julho 2011.

CASTILLO, R. Dinâmicas recentes do setor sucroenergético no Brasil: competitividade regional e expansão para o Bioma Cerrado. GEOgraphia - Ano 17 - No 35 - Dossiê, 2015.

CASTILLO, R.; FREDERICO, Samuel. Espaço geográfico, produção e movimento: uma reflexão sobre o conceito de circuito espacial produtivo. Sociedade \& Natureza, Uberlândia, 22 (3): 461-474, dez. 2010.

CESCON, F. R. P. Migração e unidades prisionais: o cenário dos pequenos municípios do Oeste paulista. Dissertação de Mestrado. Campinas: Instituto de Filosofia e Ciências Humanas - IFCH/UNICAMP, 2012.

CÔRREA, D. S. Fusões e Aquisições nos Segmentos Carne Bovina, Óleo de Soja e Sucroalcooleiro. (Tese de Doutorado) - Faculdade de Filosofia, Letras e Ciências Humanas da Universidade de São Paulo (FFLCH-USP), 2012.

CORRÊA, R. L. A rede urbana. São Paulo: Editora Ática, 1994.

DELGADO, G. Mudança técnica na agricultura, constituição do complexo agroindustrial e política tecnológica recente. Cadernos de Ciência \& Tecnologia, Brasília, 2(1): 79-97, jan. /abr., 1985. 
DEMÉTrio, N. B. População e dinâmica econômica na Região de Governo de Jales: o outro rural do Oeste Paulista. Dissertação de Mestrado. Campinas: Instituto de Filosofia e Ciências Humanas - IFCH/UNICAMP, 2013.

ELIAS, D. Globalização e Agricultura. São Paulo: EdUSP, 2003.

FAVARETO, A. Paradigmas do Desenvolvimento Rural em Questão. São Paulo: Iglu: FAPESP, 2007.

FIBGE. Censo agropecuário 2006.

FIBGE. Censo Demográfico de 1920, 1940, 1950, 1960, 1970, 1980, 1991, 2000 e 2010.

FIBGE, Séries e Estatísticas Históricas. Disponível em: http://seriesestatisticas.ibge.gov.br. Acesso: 12/01/2017

GIDDENS, A. As consequências da modernidade. São Paulo: Editora UNESP, 1991.

GONÇALVES, M. F. As engrenagens da locomotiva: ensaio sobre a formação urbana paulista. Tese de doutorado. Campinas: Instituto de Filosofia e Ciências Humanas - IFCH/UNICAMP, 1998.

HAGE, F. A. S.; PEIXOTO, M.; VIEIRA FILHO, J. E. R. Aquisição de Terras por Estrangeiros no Brasil: uma Avaliação Jurídica e Econômica. Texto para Discussão. Instituto de Pesquisa Econômica Aplicada. Brasília/Rio de Janeiro, novembro de 2012.

HARVEY, D. Condição pós-moderna: uma pesquisa sobre as origens da mudança cultural. São Paulo: Edições Loyola, 1992.

KULCSÁR, L. J.; CURTIS, K. J. Why does rural demography still matter? In: KULCSÁR, L. J.; CURTIS, K. J. (Eds.). Internetional Handbook of Rural Demography. London/New York: Springer, 2012.

MARTINE, G. As migrações de origem rural no Brasil: uma perspectiva histórica. In: Fundação SEADE. História e população: estudos sobre a América Latina. São Paulo: Fundação SEADE, 1990.

MAZZALI, L. O processo recente de reorganização agroindustrial: do complexo à organização 'em rede'. São Paulo: Editora UNESP, 2000.

MELO, B. M. de. História e memória na contramão da expansão canavieira: um estudo das formas de resistência dos sitiantes do extremo noroeste paulista. Tese de Doutorado. São Carlos: UFSCAR, 2013.

MOURA, R. Arranjos urbano-regionais no Brasil: uma análise com foco em Curitiba. Tese de doutorado. Curitiba: Programa de Pós-Graduação em Geografia. Universidade Federal do Paraná, 2009.

MÜLLER, G. A dinâmica da agricultura paulista. São Paulo: Fundação SEADE, 1985.

NEGRI, B., GONÇALVES, M. F. e CANO, W. O processo de interiorização do desenvolvimento e da urbanização no Estado de São Paulo (1920-1980). In: CANO, W. (Org.). A interiorização do desenvolvimento econômico no Estado de São Paulo (1920-1980). São Paulo: SEADE, 1988, p.5-93.

REBORATII, C. Desarrollo Regional y Territorios Privatizados. In: ACUÑA, C.; RIELLA, A. (Org). Território, Sociedad y Región: Perspectivas desde el Desarrollo Regional y Local. Montevideo: Faculdad de Ciencias Sociales, 2003.

RENNER, C. R; PATARRA, N. L. Migrações. In: SANTOS; LEYY; SZMRECSÂNYI (org). Dinâmica da População. São Paulo: T. A. Queiróz Editora, 1980.

RIBEIRO, A. C. T. Regionalização: fato e ferramenta. In: LIMONAD, E.; HAESBAERT, R.; MOREIRA, R. (org.) Brasil século XXI: Por uma regionalização? Processos, Escalas, Agentes. São Paulo: Max Limonad, 2004. p. 194212.

RIELLA, A.; MASCHERONI, P. Desigualdades sociales y territorios rurales en Uruguay. Revista Pampa, 2011.

RODRIGUES, I. A. A Demografia da Vida Rural Paulista. Tese de doutorado. Campinas: Instituto de Filosofia e Ciências Humanas - IFCH/UNICAMP, 2001.

SANT'ANA, A. L.; SILVA, F. C. da; MODENESE, V. da S.; SANT'ANA, D. Z.; SOUZA, G. dos S. Qualidade partilhada e relações de sociabilidade entre produtores familiares e consumidores no processo de comercialização direta, no noroeste paulista. In: CONTERATO; M. A.; NIERDELE, P. A.; TRICHES, R. M.; MARQUES, F. C.; SCHULTZ, G. Mercados e Agricultura Familiar: Interfaces, Conexões e Conflitos. Porto Alegre: Via Sapiens, 2013.

SANTOS, M. Técnica, espaço, tempo. São Paulo: Editora da Universidade de São Paulo, 2013 (5 $5^{\mathrm{a}}$ ed.).

SANTOS, M. A Natureza do Espaço: Técnica e Tempo, Razão e Emoção. São Paulo: Editora da Universidade de São Paulo, 2002.

SANTOS, M. A urbanização brasileira. São Paulo: HUCITEC, 1993.

SASSEN, S. As cidades na economia mundial. São Paulo: Studio Nobel, 1998.

SAWYER, D.; RIGOTTI, J. I. R. Migrantion and Spatial Distribution of Rural Population in Brazil, 1950-2050. In: 24th General Population Conference of the International Union for Scientific Study of Population (IUSSP): Salvador, September 18-24, 2001.

SILVA, J. G. da. O novo rural brasileiro. Campinas: UNICAMP. IE, 1999a.

SILVA, M. A. M. Errantes do Fim do Século. São Paulo: Fundação Editora da UNESP, 1999b.

SINGER, P. Migrações internas: considerações teóricas sobre o seu estudo. In: MOURA, H. (Org.). Migração interna: textos selecionados. Fortaleza: Banco do Nordeste do Brasil S.A., 1980.

TARTAGLIA, J.C; OLIVEIRA, O. L. Agricultura Paulista e sua Dinâmica Regional (1920-1980). In: CANO, W. (Org.). A interiorização do desenvolvimento econômico no Estado de São Paulo (1920-1980). São Paulo: SEADE, 1988, p.593.

WANDERLEY, M. N. B. Um saber necessário: os estudos rurais no Brasil. Campinas: Editora da Unicamp, 2011. 
